\title{
A Double-Quadrature Radiofrequency Coil Design for Proton-Decoupled Carbon-13 Magnetic Resonance Spectroscopy in Humans at 7T
}

\author{
Eulalia Serés Roig, ${ }^{1 *}$ Arthur W. Magill, ${ }^{2 \dagger}$ Guillaume Donati, ${ }^{1}$ Martin Meyerspeer, ${ }^{2 \ddagger}$ \\ Lijing Xin, ${ }^{1,3}$ Ozlem Ipek, ${ }^{2}$ and Rolf Gruetter ${ }^{1,3,4}$
}

Purpose: Carbon-13 magnetic resonance spectroscopy $\left({ }^{13} \mathrm{C}-\mathrm{MRS}\right)$ is challenging because of the inherent low sensitivity of ${ }^{13} \mathrm{C}$ detection and the need for radiofrequency transmission at the ${ }^{1} \mathrm{H}$ frequency while receiving the ${ }^{13} \mathrm{C}$ signal, the latter requiring electrical decoupling of the ${ }^{13} \mathrm{C}$ and ${ }^{1} \mathrm{H}$ radiofrequency channels. In this study, we added traps to the ${ }^{13} \mathrm{C}$ coil to construct a quadrature $-{ }^{13} \mathrm{C} /$ quadrature- ${ }^{1} \mathrm{H}$ surface coil, with sufficient isolation between channels to allow simultaneous operation at both frequencies without compromise in coil performance.

Methods: Isolation between channels was evaluated on the bench by measuring all coupling parameters. The quadrature mode of the quadrature- ${ }^{13} \mathrm{C}$ coil was assessed using in vitro ${ }^{23} \mathrm{Na}$ gradient echo images. The signal-to-noise ratio (SNR) was measured on the glycogen and glucose resonances by ${ }^{13} \mathrm{C}-\mathrm{MRS}$ in vitro, compared with that obtained with a linear- ${ }^{13} \mathrm{C}$ /quadrature- ${ }^{1} \mathrm{H}$ coil, and validated by ${ }^{13} \mathrm{C}-\mathrm{MRS}$ in vivo in the human calf at $7 \mathrm{~T}$. Results: Isolation between channels was better than $-30 \mathrm{~dB}$. The ${ }^{23} \mathrm{Na}$ gradient echo images indicate a region where the field is strongly circularly polarized. The quadrature coil provided an SNR enhancement over a linear coil of 1.4 , in vitro and in vivo.

Conclusion: It is feasible to construct a double-quadrature ${ }^{13} \mathrm{C}-{ }^{1} \mathrm{H}$ surface coil for proton decoupled sensitivity enhanced ${ }^{13} \mathrm{C}-\mathrm{NMR}$ spectroscopy in humans at $7 \mathrm{~T}$. Magn Reson Med 73:894-900, 2015. (c) 2014 Wiley Periodicals, Inc.

Key words: RF coils; double-quadrature; trap; ${ }^{13} \mathrm{C}-\mathrm{MRS}$; glycogen; human calf

\footnotetext{
${ }^{1}$ Laboratory of Functional and Metabolic Imaging LIFMET/EPFL, Lausanne, Switzerland.

${ }^{2}$ Centre d'Imagerie Biomédicale CIBM/EPFL, Lausanne, Switzerland.

${ }^{3}$ Department of Radiology, University of Lausanne UNIL, Lausanne, Switzerland.

${ }^{4}$ Department of Radiology, University of Geneva UNIGE, Geneva, Switzerland.

Grant sponsors: Centre d'Imagerie Biomédicale of the Université de Lausanne, Université de Genève, Hôpitaux Universitaires de Genève, Centre Hospitalier Universitaire Vaudois, Ecole Polytechnique Fédérale de Lausanne, Leenaards and Jeantet Foundations, and the NCCR Synapsy; Grant sponsor: Austrian Research Promotion Agency FFG (to M.M.); Grant number: 832107; Grant sponsor: Austrian Science Fund FWF (to M.M.); Grant number: J3031-N20.

*Correspondence to: Eulalia Serés Roig, Ecole Polytechnique Fédérale de Lausanne (EPFL), EPFL-SB-IPSB-LIFMET, Station 6, CH-1015 Lausanne, Switzerland. E-mail: eulalia.seresroig@epfl.ch

'Current affiliation: Institute of Neuroscience and Medicine, Juelich, Germany

${ }^{\ddagger}$ Current affiliation: Center for Medical and Biomedical Engineering, MR Center of Excellence, Medical University of Vienna, Vienna, Austria.

Received 25 October 2013; revised 20 December 2013; accepted 17 January 2014

DOI 10.1002/mrm.25171

Published online 3 March 2014 in Wiley Online Library (wileyonlinelibrary. com).
}

(c) 2014 Wiley Periodicals, Inc.

\section{INTRODUCTION}

Carbon-13 magnetic resonance spectroscopy $\left({ }^{13} \mathrm{C}-\mathrm{MRS}\right)$ is a powerful tool for studying metabolism in vivo (1), such as natural abundance of muscle glycogen (2), among others. However, in vivo ${ }^{13} \mathrm{C}$-NMR spectroscopy is challenging due the low natural abundance and the low concentration of ${ }^{13} \mathrm{C}$ in the human body, the unfavorable gyromagnetic ratio of the ${ }^{13} \mathrm{C}$ nucleus, and the singlebond ${ }^{1} \mathrm{H}_{-}{ }^{13} \mathrm{C}$ hetero-nuclear $\mathrm{J}$ coupling, which needs to be decoupled to enhance sensitivity (3).

Despite the improvements in sensitivity at high magnetic field strengths (4), the main limitation in human studies is the power deposition in tissue by radiofrequency (RF) pulses, especially when using ${ }^{1} \mathrm{H}$-decoupling (5).

In this context, surface coils are preferred for the optimization of the signal-to-noise ratio (SNR) $(6,7)$. Quadrature coils are advantageous relative to linear coils because they can further enhance the SNR by a factor of $\sqrt{ } 2$, reduce the transmit power by half, and provide a transversal $\mathrm{B}_{1}$ that is more homogeneous while covering a larger field of view (FOV) $(8,9)$.

A commonly used RF coil design for proton-decoupled ${ }^{13} \mathrm{C}$-MRS studies is a combination of a linear- ${ }^{13} \mathrm{C}$ coil and a quadrature- ${ }^{1} \mathrm{H}$ coil (10). A main limitation of this design is the requirement that, in order to maintain low coupling between the channels, the ${ }^{1} \mathrm{H}$ and ${ }^{13} \mathrm{C}$ coils must be accurately positioned in a geometry that ensures the two RF fields are orthogonal. It is difficult to add a second ${ }^{13} \mathrm{C}$ loop to this arrangement while maintaining orthogonal overlapping fields.

An alternative approach to dual-frequency coil design is to use a trap (a parallel inductor and capacitor) to resonate a single circuit at two frequencies $(11,12)$. More recently, traps have been applied to multinuclear coils using separate X-nuclei and proton channels (13-15). While these first designs consisted of a pair of concentric loops, the principle may be extended to more complex coil geometries, such as a quadrature- ${ }^{13} \mathrm{C}$ coil/volume- ${ }^{-1} \mathrm{H}$ coil for ${ }^{13} \mathrm{C}-\mathrm{MRS}$ in human brain at $3 \mathrm{~T}$ (16), and a double-quadrature ${ }^{31} \mathrm{P}-{ }^{1} \mathrm{H}$ surface $\mathrm{RF}$ coil design including LCC traps (a series inductor and capacitor in parallel with a second capacitor) for ${ }^{31} \mathrm{P}-\mathrm{MRS}$ in human muscle at 7T (17). Furthermore, a comparison between a singlechannel ${ }^{13} \mathrm{C}-{ }^{1} \mathrm{H}$ coil and a dual-channel ${ }^{13} \mathrm{C}-{ }^{1} \mathrm{H}$ design has been reported for hyperpolarized ${ }^{13} \mathrm{C}$ cardiac imaging at 3T, demonstrating high SNR images over an increased FOV using the dual-channel design (18). More recently a 

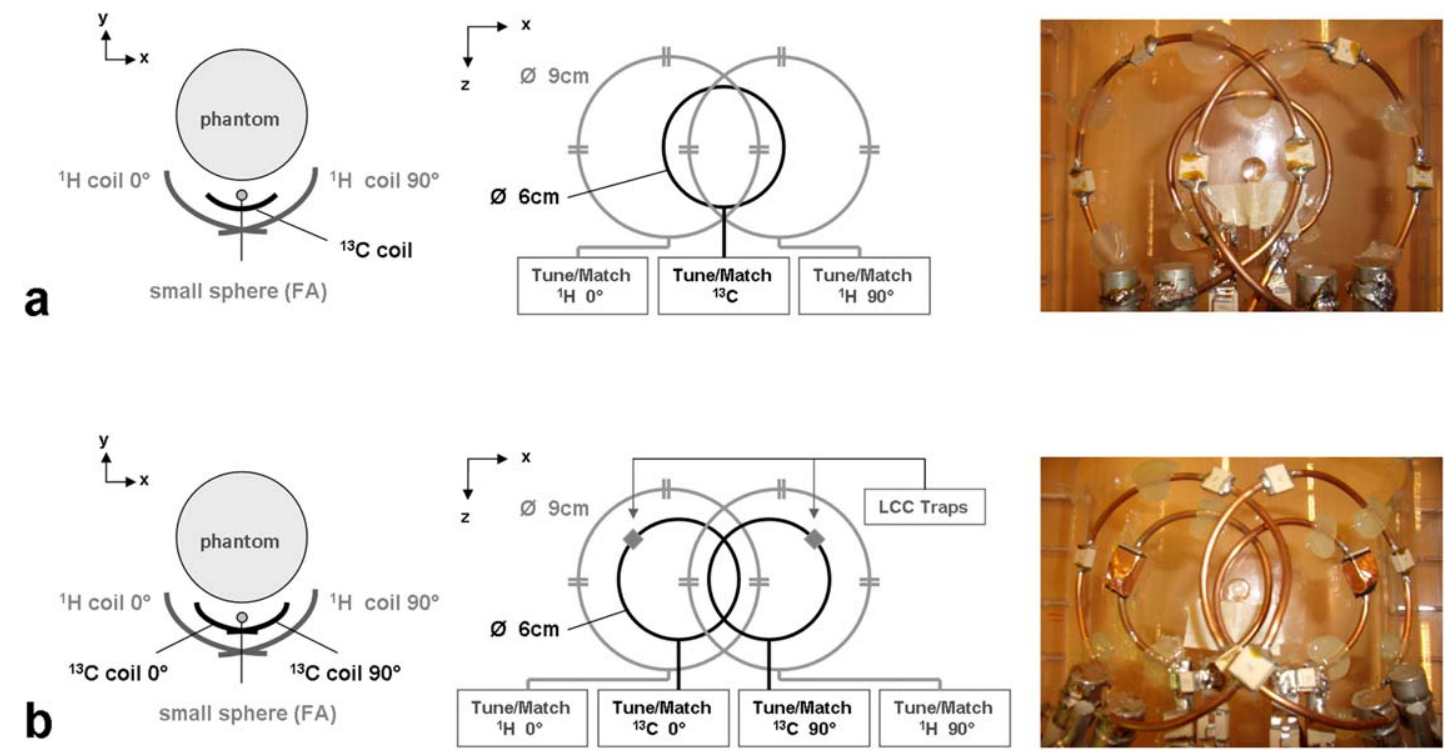

FIG. 1. Design of the (a) linear- ${ }^{13} \mathrm{C} /$ quadrature $-{ }^{1} \mathrm{H}$ and $(\mathbf{b})$ quadrature $-{ }^{13} \mathrm{C} /$ quadrature- ${ }^{1} \mathrm{H}$ coils. All quadrature pairs were decoupled by overlapping the loops. For the linear/quadrature coil, isolation between the ${ }^{13} \mathrm{C}$ loop and the ${ }^{1} \mathrm{H}$ loops was achieved geometrically. For the quadrature/quadrature coil, isolation between the ${ }^{13} \mathrm{C}$ and ${ }^{1} \mathrm{H}$ loops was achieved by inserting an LCC trap to each ${ }^{13} \mathrm{C}$ loop.

half birdcage ${ }^{13} \mathrm{C} /{ }^{1} \mathrm{H}$ coil was compared with a linear- ${ }^{13} \mathrm{C}$ /quadrature- ${ }^{1} \mathrm{H}$ design for ${ }^{13} \mathrm{C}$-MRS in humans at $3 \mathrm{~T}$ (19), the former providing a higher sensitivity and better penetration on the ${ }^{13} \mathrm{C}$ channel, but requiring more power on the ${ }^{1} \mathrm{H}$ channel.

The aim of the present study was to design and build a double-quadrature ${ }^{1} \mathrm{H}-{ }^{13} \mathrm{C}$ coil for use at $7 \mathrm{~T}$ consisting of two separate quadrature pairs, one for each nucleus, including a ${ }^{1} \mathrm{H}$ trap in each ${ }^{13} \mathrm{C}$ loop, without performance reduction in either channel, and to evaluate the performance of the resulting coil design. We demonstrate the feasibility of the double-quadrature ${ }^{1} \mathrm{H}-{ }^{13} \mathrm{C}$ coil by proton-decoupled ${ }^{13} \mathrm{C}$-MRS in vitro and in vivo while measuring natural abundance of glycogen $\mathrm{C}_{1}$ in human calf at $7 \mathrm{~T}$.

\section{METHODS}

All experiments were performed on a 7T MR human scanner (Siemens Medical Solutions, Erlangen, Germany). Informed consent was obtained from all subjects according to a procedure approved by the local ethics committee.

\section{RF Coil and Bench Measurements}

Two dual-tuned ${ }^{13} \mathrm{C}-{ }^{1} \mathrm{H}$ surface coils were built for this study, a linear- ${ }^{13} \mathrm{C} /$ quadrature- ${ }^{1} \mathrm{H}$ coil (10) and a quadrature- ${ }^{13} \mathrm{C}$ /quadrature- ${ }^{1} \mathrm{H}$ design. All bench measurements were performed using a network analyzer (E5071C; Agilent, Santa Clara, California, USA), by connecting the ${ }^{1} \mathrm{H}$ loops to ports 1 and 2 and the ${ }^{13} \mathrm{C}$ loops to ports 3 and 4 .

The linear- ${ }^{13} \mathrm{C} /$ quadrature- ${ }^{1} \mathrm{H}$ coil consisted of a combination of a quadrature- ${ }^{1} \mathrm{H}$ coil (two circular loops, 9 $\mathrm{cm}$ diameter) and a linear- ${ }^{13} \mathrm{C}$ coil (a single circular loop, $6 \mathrm{~cm}$ diameter), able to operate as both transmitter and receiver (Fig. 1a). The coil was tuned and matched to 50 $\Omega$ using three distributed fixed capacitors of $6.8 \mathrm{pF}$
(E-series; American Technical Ceramics, Huntington Station, New York, USA) on the ${ }^{1} \mathrm{H}$ loops, together with two variable capacitors (SGNM series; Sprague Goodman Electronics, Westbury, New York, USA) in each of the ${ }^{1} \mathrm{H}$ and ${ }^{13} \mathrm{C}$ loops. Isolation between coils was achieved geometrically while measuring mutual coupling matrices as described previously (10).

The quadrature- $-{ }^{13} \mathrm{C} /$ quadrature $-{ }^{1} \mathrm{H}$ coil consisted of a combination of a quadrature- ${ }^{1} \mathrm{H}$ coil (two circular loops, $9 \mathrm{~cm}$ diameter) and a quadrature $-{ }^{13} \mathrm{C}$ coil (two circular loops, $6 \mathrm{~cm}$ diameter), able to operate at both transmitter and receiver (Fig. 1b). The coil was tuned and matched as for the linear- ${ }^{13} \mathrm{C} /$ quadrature- ${ }^{1} \mathrm{H}$ coil.

Isolation between each quadrature pair $\left({ }^{1} \mathrm{H}^{-1} \mathrm{H}\right.$ and ${ }^{13} \mathrm{C}-{ }^{13} \mathrm{C}$ ) was achieved by adjusting the overlap between loops to minimize their mutual coupling, measured using the network analyzer $\left(\mathrm{S}_{12}\right.$ at $300 \mathrm{MHz}$ and $\mathrm{S}_{34}$ at $\left.75 \mathrm{MHz}\right)$. Isolation between the ${ }^{1} \mathrm{H}$ loops and the ${ }^{13} \mathrm{C}$ loops at the proton frequency was achieved by adding a proton trap to each ${ }^{13} \mathrm{C}$ loop. No traps were added to the proton loops, as strong coupling between ${ }^{13} \mathrm{C}$ and ${ }^{1} \mathrm{H}$ resonators does not occur at the ${ }^{13} \mathrm{C}$ frequency (20). The sensitivity of the ${ }^{13} \mathrm{C}$ coil is critical, so it is important to minimize losses in the traps at the ${ }^{13} \mathrm{C}$ frequency. An LCC trap design was used, consisting of a series inductor $(30 \mathrm{nH})$ and capacitor $(47$ $\mathrm{pF}$ ) in parallel with a second capacitor (12 pF), as it offers lower insertion loss than a classic LC trap (a parallel inductor and capacitor) at the low frequency while maintaining strong blocking at the high frequency $(15,17)$. Traps were placed in each ${ }^{13} \mathrm{C}$ loop at a position farthest from the capacitors in the ${ }^{1} \mathrm{H}$ loops to minimize coupling via the electric field (Fig. 1). Inductors were oriented perpendicular to the ${ }^{1} \mathrm{H}$ field to minimize coupling between the trap and the ${ }^{1} \mathrm{H}$ coil (21). Finally, the traps were shielded to further ensure isolation from the ${ }^{1} \mathrm{H}$ coil.

To assess the additional loss introduced by the trap, the performance of the trapped ${ }^{13} \mathrm{C}$ loop was evaluated 
on the bench by measuring the quality factors unloaded and loaded, and compared with that of the ${ }^{13} \mathrm{C}$ loop with a fixed capacitor $(82 \mathrm{pF})$ in place of the trap, with the ${ }^{1} \mathrm{H}$ loops absent in both cases. The performance of the traps was further verified on the bench by measuring the coupling matrices from each ${ }^{1} \mathrm{H}$ loop to each ${ }^{13} \mathrm{C}$ loop $\left(\mathrm{S}_{13}\right.$, $\mathrm{S}_{23}, \mathrm{~S}_{14}, \mathrm{~S}_{24}$ ) at $300 \mathrm{MHz}$.

To reduce common modes on the cables (22), bazooka (for ${ }^{1} \mathrm{H}$ ) and LC tank (for ${ }^{13} \mathrm{C}$ ) cable traps were built. Bazooka baluns were made using a cylindrical tube of Teflon (length $=5 \mathrm{~cm}$, diameter $=1 \mathrm{~cm}$ ) including a fixed capacitor (14 pF), covered with copper tape (35 $\mu \mathrm{m})$ over the coaxial cable (K_02252_D-08; Huber \& Suhner, Naenikon, Switzerland). The LC tank circuits were made using the coaxial cable itself by making three loops (2 $\mathrm{cm}$ diameter) in parallel with a fix capacitor $(43 \mathrm{pF})$ and were shielded in order to reduce coupling with the coil. To prevent coupling between the coil and the shield of the gradient and shim coils of the scanner, an RF shield $(23,24)$ was attached around the coil, consisting of slotted copper sheets on both sides of a thin dielectric layer (0.1 mm FR4). Two transmit/receive switches were designed and built for each coil, one for the ${ }^{1} \mathrm{H}$ channel, and one for the ${ }^{13} \mathrm{C}$ channel. Finally, RF filters were used as described previously (3) to further ensure sufficient isolation between the ${ }^{13} \mathrm{C}$ and ${ }^{1} \mathrm{H}$ channels during ${ }^{1} \mathrm{H}$ RF transmission and ${ }^{13} \mathrm{C}$ detection.

The quadrature- ${ }^{13} \mathrm{C} /$ quadrature- ${ }^{1} \mathrm{H}$ coil was evaluated on the bench by measuring the quality factors unloaded and loaded. The coil was loaded with a home-built, twocompartment phantom (25) containing $800 \mathrm{mM}$ oyster glycogen (Sigma-Aldrich, Buchs, Switzerland) (inner compartment) and $8 \mathrm{mM}\left[1-{ }^{13} \mathrm{C}\right]$ glucose (Sigma-Aldrich) (outer compartment) in solution of Dulbecco's phosphate-buffered saline (dPBS) with $\mathrm{pH} 7$ mimicking in vivo conditions of human muscle at rest. Additionally, $4 \%$ of sodium azide was added on the solution to prevent potential degradation of Glucose and Glycogen.

\section{In Vitro Measurements: ${ }^{23} \mathrm{Na}-\mathrm{MRI}$}

To evaluate the polarization of the quadrature $-{ }^{13} \mathrm{C}$ coil, two-dimensional ${ }^{23} \mathrm{Na}$-gradient echo (GRE) images were acquired in vitro. The quadrature $-{ }^{13} \mathrm{C}$ coil and transmit/ receive switch were temporally retuned to the ${ }^{23} \mathrm{Na}$ resonance frequency $(79 \mathrm{MHz}$ at $7 \mathrm{~T})$. A home-built cylindrical phantom containing $100 \mathrm{mM}$ of sodium chloride in solution with dPBS was imaged. The ${ }^{23} \mathrm{Na}$-GRE measurement was performed with the coil connected normally, and with the connections to the quadrature $-{ }^{13} \mathrm{C}$ pair reversed, to generate sensitivity profiles of the quadrature and antiquadrature modes, respectively.

Additionally, a series of two-dimensional ${ }^{23} \mathrm{Na}-\mathrm{GRE}$ images of the linear and quadrature configuration were acquired at a range of transmit voltages from $5 \mathrm{~V}$ to $75 \mathrm{~V}$ in $5 \mathrm{~V}$ steps to evaluate their sensitivity profiles along the $\mathrm{x}$ - and the $\mathrm{y}$-axes. The following parameters were used: $\mathrm{FOV}=128 \times 128 \mathrm{~mm}$; slice thickness =6 mm; matrix $=64 \times 64$; repetition time $(\mathrm{TR})=20 \mathrm{~ms}$; echo time $=3.7 \mathrm{~ms}$; number of excitations $=200$; bandwidth $=260 \mathrm{~Hz}$; flip angle $=25^{\circ}$. SNR maps were generated by dividing the GRE images by the standard deviation of the noise in an image acquired with no transmit pulse $\left(\mathrm{V}_{\mathrm{TX}}=0 \mathrm{~V}\right)$.

\section{In Vitro Measurements: ${ }^{13} \mathrm{C}-\mathrm{MRS}$}

To investigate the performance of the double-quadrature ${ }^{13} \mathrm{C}-{ }^{1} \mathrm{H}$ RF coil, ${ }^{13} \mathrm{C}-\mathrm{MRS}$ measurements were performed in vitro.

First, the transmit efficiency of the ${ }^{1} \mathrm{H}$ channel of quadrature- ${ }^{13} \mathrm{C} /$ quadrature- ${ }^{1} \mathrm{H}$ and linear- ${ }^{13} \mathrm{C} /$ quadrature- ${ }^{1} \mathrm{H}$ coils was compared. A pulse sequence was implemented for ${ }^{13} \mathrm{C}$-MRS using an adiabatic half passage pulse for excitation (2050 $\mu$ s), one-dimensional (1D) ISIS (26) for localization (5120 $\mu \mathrm{s})$, and WALTZ-16 $(27,28)$ to achieve broadband ${ }^{1} \mathrm{H}$-decoupling during ${ }^{13} \mathrm{C}$ signal acquisition. The RF power required for WALTZ16 to decouple glucose $\beta$ on-resonance in the phantom was calibrated by increasing the ${ }^{1} \mathrm{H}$ transmit voltage from $10 \mathrm{~V}$ to $150 \mathrm{~V}$ in $10 \mathrm{~V}$ steps. The following NMR protocol was used: $\mathrm{TR}=3 \mathrm{~s}$; number of averages $=64$; vector size $=2048$; bandwidth $=20 \mathrm{kHz}$; 1D ISIS slice (parallel to the coil plan $160 \times 160 \times 10 \mathrm{~mm}$ ); acquisition time $=102 \mathrm{~ms}$; decoupling duration was chosen to cover the free induction decay $(87 \mathrm{~ms})$. The resulting ${ }^{13} \mathrm{C}-\mathrm{NMR}$ spectra were processed using MATLAB (MathWorks Inc, Natick, Massachusetts, USA). Data were zerofilled by a factor of 4 (to 8192 points) and apodized using a Lorentzian filter with $15 \mathrm{~Hz}$ broadening.

Second, the SNR was measured in the phantom and compared with that obtained with the linear- ${ }^{13} \mathrm{C} /$ quadrature- ${ }^{1} \mathrm{H}$ coil. The SNR was measured on the ${ }^{13} \mathrm{C}$ resonances of glycogen and glucose by measuring the ratio of the integral of the resonance peak divided by the standard deviation of the noise in a region of the spectra with no signal. The peak integral, rather than amplitude, was chosen for SNR measurement to reduce sensitivity to variations in $B_{0}$.

\section{In Vivo Measurements: ${ }^{13} \mathrm{C}-\mathrm{MRS}$ in Human Muscle}

To demonstrate use of the quadrature- ${ }^{13} \mathrm{C} /$ quadrature $-{ }^{1} \mathrm{H}$ coil in vivo, ${ }^{13} \mathrm{C}$-MRS was performed in the human calf of a healthy male volunteer. A small sphere containing $99 \%{ }^{13} \mathrm{C}$-enriched formic acid was placed at the center of the linear and quadrature- ${ }^{13} \mathrm{C}$ coils to be used as an external reference $(3,29)$. The in vivo NMR protocol included a pulse-acquire sequence with adiabatic half passage $(2050 \mu \mathrm{s}){ }^{13} \mathrm{C}$ excitation, together with WALTZ$16(20 \mathrm{~ms}){ }^{1} \mathrm{H}$-decoupling during acquisition $(\mathrm{TR}=1 \mathrm{~s}$, 256 averages, vector size $=2048$, acquisition time $=102$ ms, bandwidth $=20 \mathrm{kHz}$ ). Shimming was adjusted using first- and second-order FAST(EST)MAP (30). The SNR was measured on the glycogen $\mathrm{C}_{1}$ resonance and compared with that obtained with the linear- ${ }^{13} \mathrm{C} /$ quadrature- ${ }^{1} \mathrm{H}$ coil.

\section{RESULTS}

The ratio of unloaded to loaded $Q$ factors of the coils was 1.6 and 2.1 for the ${ }^{13} \mathrm{C}$ loops, and 2.4 and 2.6 for the ${ }^{1} \mathrm{H}$ loops, while the coil was loaded with the twocompartment phantom described above. Isolation of the four channels $\left(S_{13}, S_{23}, S_{14}, S_{24}\right)$ was better than $-30 \mathrm{~dB}$ 
Table 1

Measurement of the Mutual Coil Coupling (S-Parameters) at the ${ }^{13} \mathrm{C}$ Frequency $(75 \mathrm{MHz})$ and at the ${ }^{1} \mathrm{H}$ Frequency $(300 \mathrm{MHz})$

\begin{tabular}{|c|c|c|c|c|c|c|c|c|}
\hline & \multicolumn{8}{|c|}{$\mathrm{S}_{\mathrm{ij}(\mathrm{dB})}$} \\
\hline & \multicolumn{4}{|c|}{$75 \mathrm{MHz}$} & \multicolumn{4}{|c|}{$300 \mathrm{MHz}$} \\
\hline & ${ }^{1} \mathrm{H} 0^{\circ}$ & ${ }^{1} \mathrm{H} 90^{\circ}$ & ${ }^{13} \mathrm{C}^{\circ}$ & ${ }^{13} \mathrm{C} 90^{\circ}$ & ${ }^{1} \mathrm{HO} 0^{\circ}$ & ${ }^{1} \mathrm{H} 90^{\circ}$ & ${ }^{13} \mathrm{C}^{\circ}$ & ${ }^{13} \mathrm{C} 90^{\circ}$ \\
\hline${ }^{1} \mathrm{HO}^{\circ}$ & - & - & -30 & -18 & -40 & -16 & -31 & -37 \\
\hline${ }^{1} \mathrm{H} 90^{\circ}$ & - & - & -18 & -32 & -16 & -37 & -30 & -32 \\
\hline${ }^{13} \mathrm{C} 0^{\circ}$ & -30 & -18 & -58 & -14 & -31 & -30 & - & - \\
\hline${ }^{13} \mathrm{C} 90^{\circ}$ & -18 & -32 & -14 & -43 & -37 & -32 & - & - \\
\hline
\end{tabular}

The coil was loaded with a home-built, two-compartment phantom containing $800 \mathrm{mM}$ oyster glycogen (inner compartment) and $8 \mathrm{mM}$ $\left[1-{ }^{13} \mathrm{C}\right]$ glucose (outer compartment) in a solution of dPBS.

at $300 \mathrm{MHz}$ (Table 1), indicating good trap performance. The unloaded $\mathrm{Q}$ factor of the single trapped ${ }^{13} \mathrm{C}$ loop was reduced by only $12 \%$ with respect to that of a ${ }^{13} \mathrm{C}$ loop with a fixed capacitor in place of the trap, while $\mathrm{Q}$ factors of the loaded coils were the same, within experimental error, in agreement with previous results (15). Positioning of RF cables had no effect on the aforementioned parameters, suggesting efficient removal of common mode currents. When inserting the RF coil into the scanner, no frequency shift was observed, suggesting an effective RF shielding. The placement of a ${ }^{13} \mathrm{C}$ band-pass filter after the ${ }^{13} \mathrm{C}$ preamplifier resulted in complete absence of spikes or other interference from the ${ }^{1} \mathrm{H}$ decoupling signal during acquisition.

The ${ }^{23} \mathrm{Na}$ SNR maps of the retuned quadrature $-{ }^{13} \mathrm{C}$ coil indicate a region where there is strong signal in the positive rotating component and very little signal in the counter-rotating component (Fig. 2b, 2c), indicating that the field is strongly circularly polarized. Furthermore, an increased sensitive volume at the edges of the field of view is observed in the rotating component (Fig. 2b) compared with that of the linear- ${ }^{13} \mathrm{C}$ coil (Fig. 2a), while
FIG. 2. a-c: In vitro ${ }^{23} \mathrm{Na}$ SNR maps using (a) a linear- ${ }^{23} \mathrm{Na}$ /quadrature- ${ }^{-1} \mathrm{H}$ coil, (b) a quadrature $-{ }^{23} \mathrm{Na}$ /quadrature- ${ }^{1} \mathrm{H}$ coil with the ${ }^{23} \mathrm{Na}$ pair driven in quadrature, and (c) the same coil with the ${ }^{23} \mathrm{Na}$ pair driven in antiquadrature. d-g: SNR profiles along the (d, e) $x$-axis and (f, g) y-axis, as indicated in the ${ }^{23} \mathrm{Na}$-GRE images, while increasing the transmit voltage from $5 \mathrm{~V}$ to $75 \mathrm{~V}$. The quadrature- ${ }^{23} \mathrm{Na}$ coil provides an increased sensitive volume along the $x$ axis $(b, e)$ relative to the linear ${ }^{23} \mathrm{Na}$ coil $(\mathrm{a}$, d), whereas both coils require similar voltage to achieve a $90^{\circ}$ nutation (f, g). linear- ${ }^{13} \mathrm{C}$ coil

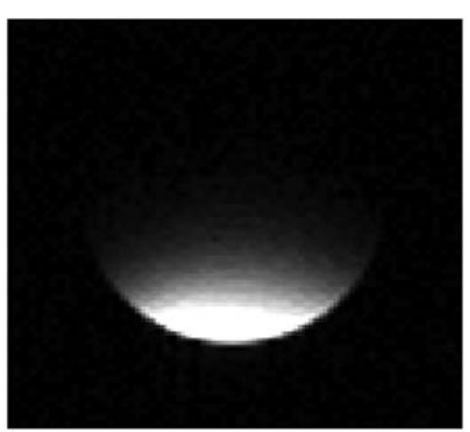

a
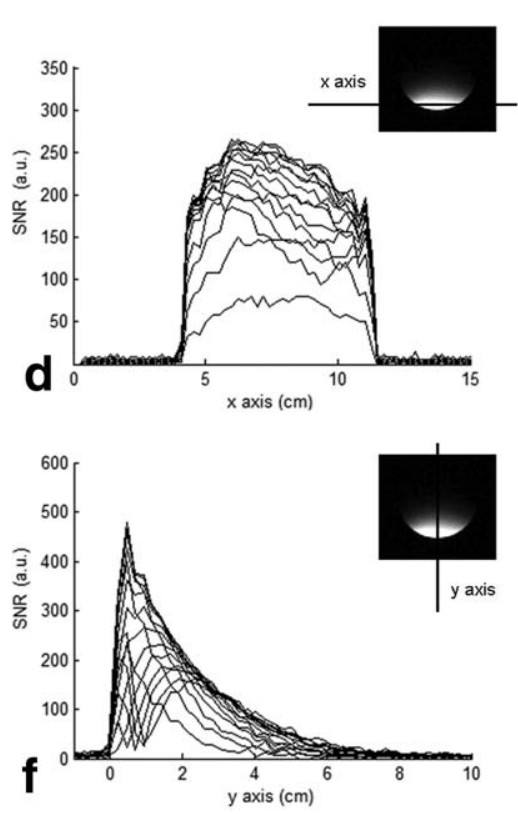

quadrature- ${ }^{13} \mathrm{C}$ coil

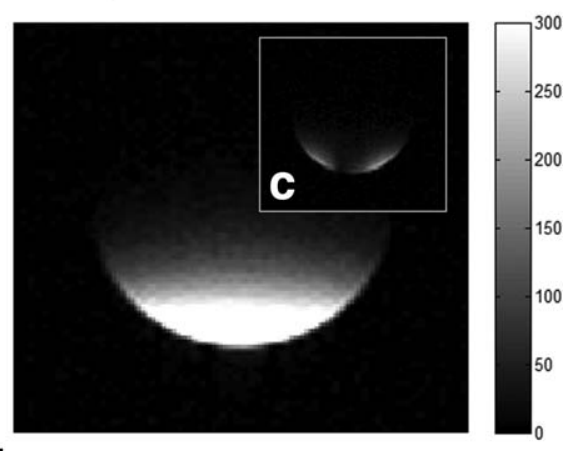

b
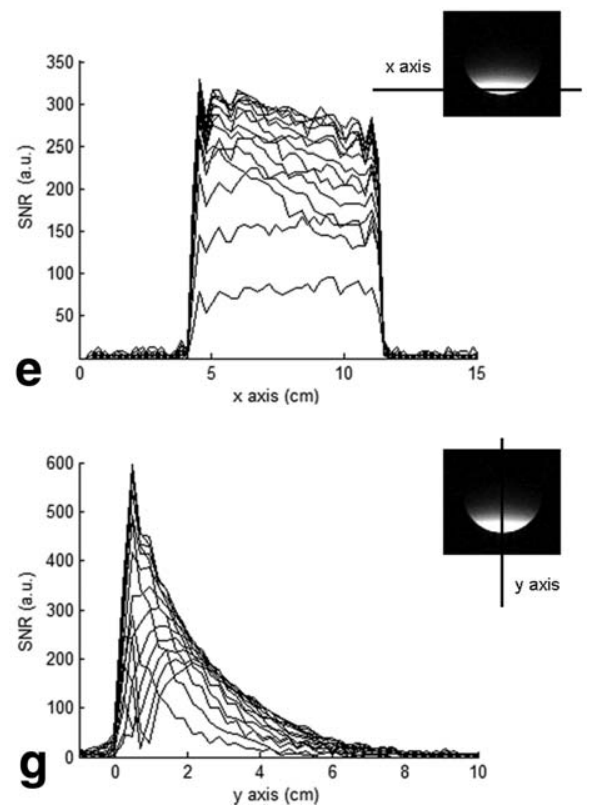


\section{Linear- ${ }^{13} \mathrm{C} /$ quadrature- ${ }^{1} \mathrm{H}$}

Double-quadrature ${ }^{13} \mathrm{C}-{ }^{1} \mathrm{H}$

Glucose $\beta$

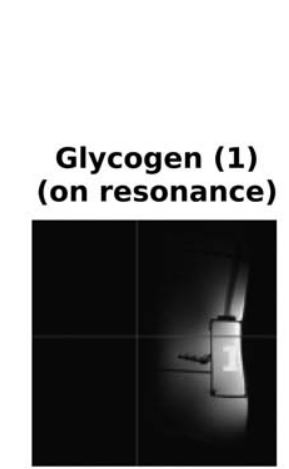

a

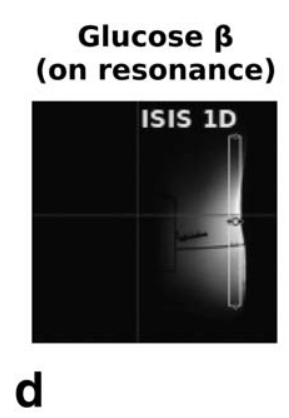

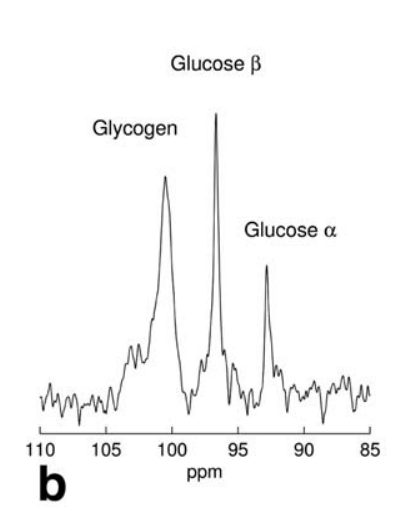

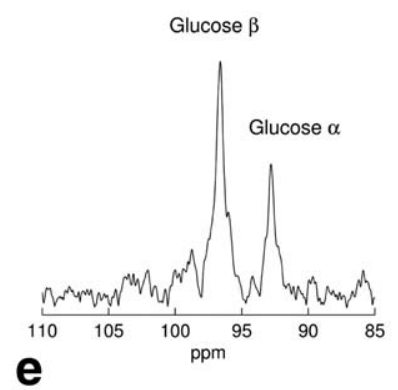

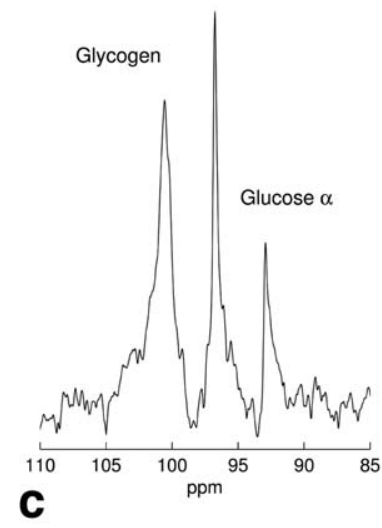

Glucose $\beta$

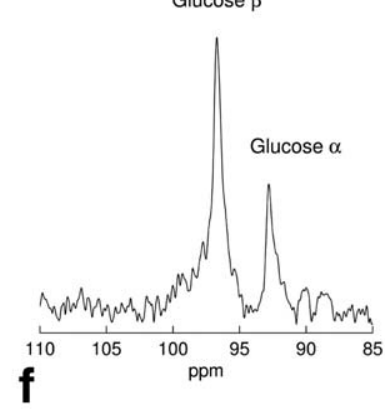

FIG. 3. a-f: In vitro proton-decoupled ${ }^{13} \mathrm{C}$ NMR spectra with $(a-c)$ glycogen or $(d-f)$ glucose $\beta$ on-resonance, showing an SNR enhancement of $\sqrt{ } 2$ when using (c, $f$ ) the quadrature- ${ }^{13} \mathrm{C} /$ quadrature- ${ }^{1} \mathrm{H}$ coil relative to $(b, e)$ the linear- ${ }^{13} \mathrm{C} /$ quadrature- ${ }^{1} \mathrm{H}$ coil. Spectra $(b, c)$ and $(e, f)$ are shown with the same vertical scales. Measurements with glucose $\beta$ on-resonance were localized using 1D ISIS to the box indicated in panel d. g: Voltage calibration for WALTZ-16 decoupling, demonstrating that the voltage required to decouple glucose $\beta$ using the quadrature- ${ }^{13} \mathrm{C} /$ quadrature- ${ }^{1} \mathrm{H}$ coil (solid line) was similar to that required using the linear- ${ }^{13} \mathrm{C}$ /quadrature- ${ }^{1} \mathrm{H}$ coil (dashed line).

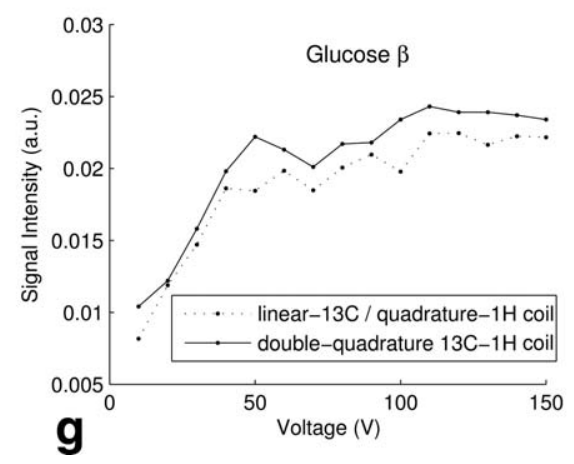

the profile along the $\mathrm{x}$-axis was nearly constant (Fig. 2e) in contrast to the linear coil (Fig. 2d), resulting in an increased sensitive volume in the $\mathrm{x}$-direction. The profiles along the $\mathrm{y}$-axis indicate that the highest $\mathrm{B}_{1}$ field produced by both linear and quadrature coils (Fig. 2f, $2 \mathrm{~g}$ ) was achieved at similar voltage close to the coil plane, while a decrease to about $50 \%$ of the maximum sensitivity was measured at a depth of $2 \mathrm{~cm}$ into the sample on a line through the center of the coil. When the transmit voltage is greater than $30 \mathrm{~V}$, a signal drop is visible in both y-axis profiles (Fig. 2f, 2g) at depths of 2 $\mathrm{cm}$ and less, due to spin nutation beyond $90^{\circ}$. As the transmit voltage is further increased above $60 \mathrm{~V}$, spins at a depth of $<1 \mathrm{~cm}$ are nutated beyond $180^{\circ}$, causing the signal intensity to increase again close to the coil while still decreasing further from it (ie, at depth $d<1 \mathrm{~cm}$, the flip angle $\theta>180^{\circ}$, while for $1 \mathrm{~cm}<d<2 \mathrm{~cm}$, $90^{\circ}<\theta<180^{\circ}$.
An SNR enhancement of $\sqrt{2}$ in the phantom was obtained while measuring carbon resonances of glycogen (100.5 ppm) (Fig. 3a-3c) and glucose $\beta$ (96.6 ppm) (Fig. $3 \mathrm{~d}-3 \mathrm{f})$, the latter including ISIS localization. Note that the SNR enhancement obtained with the double-quadrature ${ }^{13} \mathrm{C}-{ }^{1} \mathrm{H}$ coil did not require increased $\mathrm{RF}$ power on the ${ }^{1} \mathrm{H}$ channel for decoupling, compared to that required for the linear- ${ }^{13} \mathrm{C} /$ quadrature- ${ }^{1} \mathrm{H}$ coil (Fig. 3g).

The resulting in vivo nonlocalized proton-decoupled ${ }^{13} \mathrm{C}$ spectrum of the human calf (Fig. 4) included ${ }^{13} \mathrm{C}$ resonances of natural abundance of glycogen $\mathrm{C}_{1}(100.5$ ppm), fatty lipid (130 ppm), and glycerol (63 ppm and 72 ppm). An SNR enhancement of nearly 1.4 was obtained, relative to the linear- ${ }^{13} \mathrm{C} /$ quadrature- ${ }^{1} \mathrm{H}$ coil. As with the phantom, the SNR enhancement obtained with the double-quadrature ${ }^{13} \mathrm{C}-{ }^{1} \mathrm{H}$ coil did not require increased $\mathrm{RF}$ power in vivo on the ${ }^{1} \mathrm{H}$ channel while using ${ }^{1} \mathrm{H}$-decoupling. 
FIG. 4. In vivo ${ }^{13} \mathrm{C}-\mathrm{NMR}$ spectrum showing detection of the calf muscle glycogen resonance from a male subject at $100.5 \mathrm{ppm}$, acquired in $4 \mathrm{~min}, 15 \mathrm{~s}$, using the quadrature- ${ }^{13} \mathrm{C}$ /quadrature- ${ }^{-1} \mathrm{H}$ surface coil, 2 -ms pulse acquire with adiabatic excitation, 20ms WALTZ-16 decoupling, $T R=1 \mathrm{~s}$, bandwidth $=20 \mathrm{kHz}, 256$ scans, vector size $=2048$, zero filling $=2048$, and Gaussian function $\left(\exp \left(-\mathrm{t}^{2} / 2 .(0.02)(2)\right)\right)$ applied to the free induction decay prior to Fourier transform.

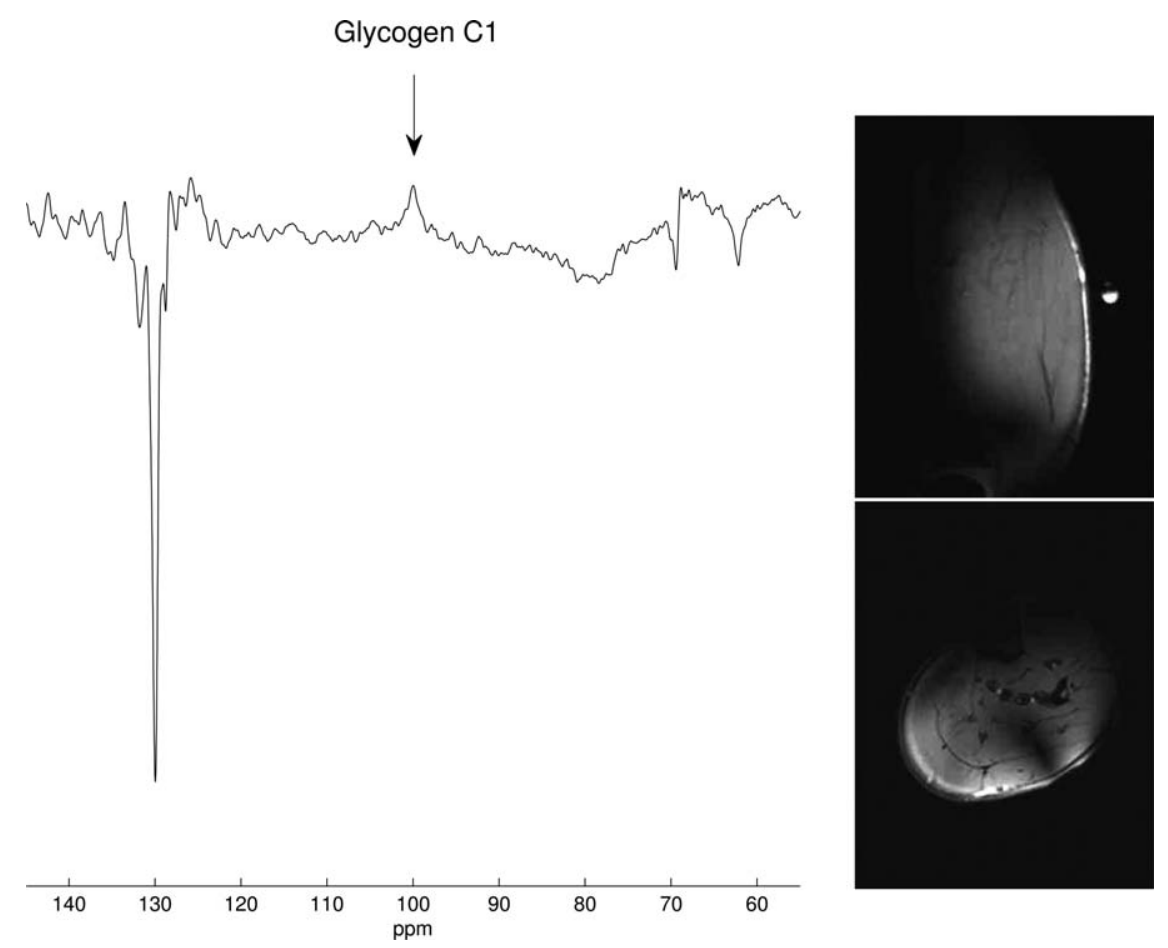

\section{DISCUSSION}

This study reports the design, construction, and evaluation of a quadrature $-{ }^{13} \mathrm{C} /$ quadrature- ${ }^{1} \mathrm{H}$ surface coil for ${ }^{13} \mathrm{C}-\mathrm{NMR}$ spectroscopy in humans at $7 \mathrm{~T}$.

Six major goals were evaluated for this coil design, namely isolation between channels, performance of the trap, quadrature mode of the quadrature $-{ }^{13} \mathrm{C}$ coil, improved SNR, reduced RF transmit voltage, and feasibility of the coil design by ${ }^{13} \mathrm{C}-\mathrm{NMR}$ spectroscopy in vivo in the human calf at $7 \mathrm{~T}$.

Isolation between each quadrature-pair was achieved by overlapping the loops (31), while isolation between ${ }^{1} \mathrm{H}$ and ${ }^{13} \mathrm{C}$ channels $\left(\mathrm{S}_{13}, \mathrm{~S}_{14}, \mathrm{~S}_{23}, \mathrm{~S}_{24}\right)$ was achieved at $300 \mathrm{MHz}$ using an LCC trap $(15,17)$. Each ${ }^{1} \mathrm{H}$ loop was well-decoupled from each ${ }^{13} \mathrm{C}$ loop at $300 \mathrm{MHz}$ (Table 1). Isolation between channels was reproducible when loading the coil either with a phantom or human leg, and was consistently below $-30 \mathrm{~dB}$ in all subjects. A second resonance was observed on the network analyzer at $327 \mathrm{MHz}$, attributed to the higher frequency resonance of the ${ }^{13} \mathrm{C}$ loop, known as "trap mode," well above the ${ }^{1} \mathrm{H}$ resonance frequency (300 $\mathrm{MHz}$ ) and not used.

The excellent performance of the traps was evident by the high isolation between channels, and no coupling was observed at $300 \mathrm{MHz}$ when the quadrature $-{ }^{13} \mathrm{C}$ coil or individual ${ }^{13} \mathrm{C}$ coil was inserted within the quadrature- ${ }^{1} \mathrm{H}$ coil, even when the ${ }^{13} \mathrm{C}$ loop was placed at different positions within the quadrature- ${ }^{1} \mathrm{H}$ coil.

When reversing the connections of the ${ }^{13} \mathrm{C}$ coil (antiquadrature configuration), a residual antiquadrature signal was observed on the edges of the field of view in the ${ }^{23} \mathrm{Na}$ images, attributed to the predominantly linear polarization of the ${ }^{13} \mathrm{C} \mathrm{B}_{1}$ in this region. Note that a clear void was detected at the center, demonstrating that $B_{1}$ polarization was close to quadrature.
The RF power required on the ${ }^{1} \mathrm{H}$ channel was similar to that required by the linear- ${ }^{13} \mathrm{C} /$ quadrature $-{ }^{1} \mathrm{H}$ coil, while the SNR was enhanced by 1.4 in vitro and in vivo, close that expected from theory.

The dimensions of the coil and its support are compatible for further in vivo ${ }^{13} \mathrm{C}$-MRS studies in other organs (eg, the human brain), as has been the case for the linear- ${ }^{13} \mathrm{C}$ /quadrature- ${ }^{1} \mathrm{H}$ coil (10), upon which the current design is based. Furthermore, the $\mathrm{X}$-nuclei quadrature design could be extended into an array design for studies requiring signal enhancement in deeper areas which, in terms of coil design, require a larger FOV.

\section{CONCLUSION}

It is feasible to construct a double-quadrature ${ }^{13} \mathrm{C}-{ }^{1} \mathrm{H}$ surface coil for proton-decoupled ${ }^{13} \mathrm{C}$-NMR spectroscopy in humans at 7T. The coil design presented in this study was based on the use of traps inserted in the quadrature $-{ }^{13} \mathrm{C}$ coil to ensure sufficient isolation between ${ }^{1} \mathrm{H}$ and ${ }^{13} \mathrm{C}$ channels, which allowed the measurement of glycogen $\mathrm{C}_{1}$ natural abundance in the human calf at $7 \mathrm{~T}$, providing an SNR enhancement of nearly $\sqrt{2}$, without increasing the $\mathrm{RF}$ power on the ${ }^{1} \mathrm{H}$ channel while receiving ${ }^{13} \mathrm{C}$ signal. The sensitivity enhancement obtained with this coil design should allow further extension of ${ }^{13} \mathrm{C}-\mathrm{NMR}$ spectroscopy such as in the human brain.

\section{REFERENCES}

1. Rothman DL, De Feyter HM, de Graaf RA, Mason GF, Behar KL. ${ }^{13} \mathrm{C}$ MRS studies of neuroenergetics and neurotransmitter cycling in humans. NMR Biomed 2011;24:943-957.

2. Avison MJ, Rothman DL, Nadel E, Shulman RG. Detection of human muscle glycogen by natural abundance ${ }^{13} \mathrm{C}$ NMR. Proc Natl Acad Sci U S A 1988;85:1634-1636. 
3. Gruetter R, Adriany G, Choi IY, Henry PG, Lei H, Oz G. Localized in vivo ${ }^{13} \mathrm{C}$ NMR spectroscopy of the brain. NMR Biomed 2003;16:313-338.

4. Gruetter R, Adriany G, Merkle H, Andersen PM. Broadband decoupled, ${ }^{1} \mathrm{H}$-localized ${ }^{13} \mathrm{C}$ MRS of the human brain at 4 Tesla. Magn Reson Med 1996;36:659-664.

5. Deelchand DK, Ugurbil K, Henry PG. Investigating brain metabolism at high fields using localize ${ }^{13} \mathrm{C}$ NMR spectroscopy without ${ }^{1} \mathrm{H}$ decoupling. Magn Reson Med 2006;55:279-286.

6. Hoult DI, Richards RE. The signal-to-ratio of the nuclear magnetic resonance experiment. 1976. J Magn Reson 2011;213:329-343.

7. Haase A, Odoj F, Von Kienlin M, et al. NMR probeheads for in vivo applications. Concepts Magn Res 2000;12:361-388.

8. Hoult DI, Chen CN, Sank VJ. Quadrature detection in the laboratory frame. Magn Reson Med 1984;1:339-353.

9. Chen CN, Hoult DI, Sank VJ. Quadrature detection coils. A further $\sqrt{ } 2$ improvement in sensitivity. J Magn Reson 1983;(54):324-327.

10. Adriany G, Gruetter R. A half-volume coil for efficient proton decoupling in humans at 4 Tesla. J Magn Reson 1997;125:178-184.

11. Schnall MD, Subramanian VH, Leight JS, Chance B. A new doubletuned probe for concurrent ${ }^{1} \mathrm{H}$ and ${ }^{31} \mathrm{P}$ NMR. J Magn Reson 1985;65: 122-129.

12. Isaac G, Schnall MD, Lenkinski RE, Vogele K. A design for a doubletuned birdcage coil for use in an integrated MRI/MRS examination. J Magn Reson Imaging 1990;89:41-50.

13. Alecci M, Romanzetti S, Kaffanke J, Celik A, Wegener HP, Shah NJ. Practical design of a 4 tesla double-tuned RF surface coil for interleaved ${ }^{1} \mathrm{H}$ and ${ }^{23} \mathrm{Na}$ MRI of rat brain. J Magn Reson Imaging 2006;181: 203-211.

14. Dabirzadeh A, McDougall MP. Trap design for insertable second-nuclei radiofrequency coils for magnetic resonance imaging and spectroscopy. Concepts Magn Reson Part B Magn Reson Eng 2009;35B:121-132.

15. Meyerspeer M, Serés Roig E, Gruetter R, Magill AW. An improved trap design for decoupling multinuclear RF coils. Magn Reson Med 2014;72:584-590.

16. Klomp DWJ, Renema WKJ, Van der Graaf M, de Galan DE, Kentgens APM, Heerschap A. Sensitivity-enhanced ${ }^{13} \mathrm{C}$ MR spectroscopy of the human brain at 3 Tesla. Magn Reson Med 2006;55:271-278.

17. Webb A, Smith N. ${ }^{31} \mathrm{P}$ spectroscopy in human calf muscle at 7 Tesla using a balanced double-quadrature proton-phophorus RF coil. Proceed- ings of the 18th Annual Meeting of ISMRM, Stockholm, Sweden, 2010. p. 3818.

18. Dominguez-Viqueira W, Lau AZ, Chen AP, Cunningham CH. Multichannel receiver coils for improved coverage in cardiac metabolic imaging using prepolarized ${ }^{13} \mathrm{C}$ substrates. Magn Reson Med 2013;70: 295-300.

19. Yahya A, De Zanche N, Allen PS. A dual-tuned transceiver resonator for ${ }^{13} \mathrm{C}\left\{{ }^{1} \mathrm{H}\right\}$ MRS: two open coils in one. NMR Biomed 2013;26:533-541.

20. Fitzsimmons JR, Beck BL, Brooker HR. Double resonant quadrature birdcage. Magn Reson Med 1993;30:107-114.

21. Shen GX, Boada FE, Thulborn KR. Dual-frequency, dual-quadrature, birdcage RF coil design with identical $\mathrm{B}_{1}$ pattern for sodium and proton imaging of the human brain at 1.5T. Magn Reson Med 1997;38: 717-725.

22. Peterson DM, Beck BL, Duensing GR, Fitzsimmons JR. Common mode signal rejection methods for MRI: reduction of cable shield currents for high static magnetic field systems. Concepts Magn Reson Part B Magn Reson Eng 2003;19B:1-8.

23. Jin JM. Electromagnetic analysis and design in magnetic resonance imaging. Boca Raton, Florida: CRC Press; 1999.

24. Hayes E, Eash MG. Shield for decoupling RF and gradient coils in an NMR apparatus. US patent 4642 569. February 10, 1987.

25. Serés Roig E, Xin L, Magill AW, Gruetter R. Towards ${ }^{13} \mathrm{C}$ NMR spectroscopy of human muscle at $7 \mathrm{~T}$ using broadband ${ }^{1} \mathrm{H}$ decoupling. Proceedings of the 20th Annual Meeting of ISMRM, Melbourne, Australia, 2012. p. 4425.

26. Ordidge RJ, Connelly A, Lohman JAB. Image-selected in vivo spectroscopy (ISIS). A new technique for spatially selective NMR spectroscopy. J Magn Reson 1986;66:283-294.

27. Shaka AJ, Keeler J, Frenkiel T, Freeman R. An improved sequence for broadband decoupling: WALTZ-16. J Magn Reson 1983;52:335-338.

28. Shaka AJ, Keeler J, Freeman R. Evaluation of a new broadband decoupling sequence: WALTZ-16. J Magn Reson 1983;53:313-340.

29. Bax A. A Simple method for the calibration of the decoupler radiofrequency field strength. J Magn Reson 1983;52:76-80.

30. Gruetter R, Tkac I. Field mapping without reference scan using asymmetric echo-planar techniques. Magn Reson Med 2000;43:319-323.

31. Roemer PB, Edelstein WA, Hayes CE, Souza SP, Mueller OM. The NMR phase array. Magn Reson Med 1990;16:192-225. 